\title{
The role of working environment in nurses' career advancement from nursing mangers' perspectives: A qualitative study
}

\author{
Mohammad Reza Sheikhi ${ }^{1}$, Masoud Fallahi Khoshknab*1, Farahnaz Mohammadi ${ }^{2}$, Fatemeh Oskouie ${ }^{3}$ \\ ${ }^{1}$ Department of Nursing, University of Social Welfare \& Rehabilitation Sciences (USWR), Tehran, Iran \\ ${ }^{2}$ Social Determinant of Health Research Center and Department of Nursing, University of Social Welfare and Rehabilitation \\ Sciences, Tehran, IR, Iran \\ ${ }^{3}$ Center for Nursing Care Research and School of Nursing and Midwifery, Iran University of Medical Sciences, Tehran, Iran
}

Received: January 26, 2016

DOI: $10.5430 /$ jha.v5n4p49

\author{
Accepted: April 7, 2016 \\ Online Published: May 4, 2016 \\ URL: http://dx.doi.org/10.5430/jha.v5n4p49
}

\begin{abstract}
Background: Nurses' career advancement is a dynamic and unique concept which is explained in the context of working environment.

Objective: This study aimed to explore the role of working environment in nurses' career advancement from Nursing Mangers' Perspectives.

Methods: This qualitative study was conducted using content analysis method. Eighteen nursing managers from hospitals affiliated to Qazvin, Tehran, Iran and Shahid Beheshti Medical Sciences Universities participated in the study. A purposive sample of nursing mangers with rich experiences and maximum variations were selected and continued to reaching data saturation. The data were analyzed using content analysis method.

Results: Participants believed that working environment have two major roles in nurses' career advancement including motivating and restricting roles. According to nursing mangers, motivating working environment had facilitating role, while restricting working environment had blocking role in Iranian nurses' career advancement.

Conclusions: It seems that recognizing characteristics of working environment could assist nurses and nursing managers to develop conditions of working environment facilitating career advancement for nurses and decrease restrictive factors.
\end{abstract}

Key Words: Career mobility, Working place, Nurses, Qualitative research

\section{INTRODUCTION}

Healthcare organizations are considered fundamentals in health system and influence considerably on health promotion in the community. ${ }^{[1]}$ The foundation of forming these organizations is based on human resources. ${ }^{[2,3]}$ These organisations are facilitating conditions of career advancement on the basis of changing technology and knowledge, staff expectations, the necessity of decreasing cost and increasing productivity. ${ }^{[4,5]}$ In addition to providing high quality services, these organisations are making attempt to provide opportunities for staff advancement. ${ }^{[6]}$

Career advancement is a formal and structured activity that

\footnotetext{
*Correspondence: Masoud Fallahi Khoshknab; Email: fallahi@uswr.ac.ir; Address: Department of nursing, University of Social Welfare and Rehabilitation Sciences, Koodakyar, Evin, Tehran, Iran.
} 
heath institutes plan for increasing staff awareness on factors affecting career, knowledge advancement and staff capabilities. ${ }^{[7]}$ This structure consists of any professional promotions that result in identification, awarding and further payment in nursing practice or management. ${ }^{[4]}$ Furthermore, it provides opportunities for nurses to increase their capabilities and participate in professional promotion. ${ }^{[8]}$ Nurses' career advancement is influence by several intrapersonal factors, interpersonal factors and organisational determinants. ${ }^{[7]}$ Intrapersonal factors include nurses' personality characteristics, self-efficacy, psychological factors and personal motivates. ${ }^{[9]}$ While, interpersonal interactions, peer networks and supportive working environment constitute interpersonal factors. ${ }^{[10]}$ Continuing education, family support, and nurse' participation influence on determinant of human resources. ${ }^{[11]}$ Each of these factors could impact nurses' career advancement directly or indirectly. ${ }^{[4,12]}$

Literature review indicates that organisational characteristics are considered as affecting indices on career advancement. ${ }^{[7-10]}$ Organisational features such as working environment influence nurses' career advancement through empowerment. ${ }^{[6]}$ Inappropriate working environment contribute to leaving nursing profession, decreasing persistence and a barrier to nurses' career advancement. ${ }^{[13]}$ Ulrich et al. reported that more than $50 \%$ of nurses believe lack of appropriate opportunity in their working environment. ${ }^{[14]}$ Cleary et al. stated that lack of support in working environment, inadequate opportunities for career advancement, extra working hours, and lack of access to education are factors in the working environment that considered as barriers to career advancement from graduate nurses' perspectives. ${ }^{[10]}$ Adeniran found that although attention has been made to nurses' career advancement over recent decades in the USA, more than one-third of clinical nurses with 10 years of experience or more have still not able to promote in their careers. ${ }^{[4]}$ Riley et al. stated that lack of opportunities for career advancement is the most important factor of nurses' dissatisfaction in clinical settings. In the USA, only $32.2 \%$ of nurses are able to promote in their careers, and some factors influence on nurses career advancement indirectly. ${ }^{[15]}$ It has been found that providing conditions of continuing education facilitates the possibility of career advancement. Factors hindering continuing education could block nurse's career advancement indirectly. ${ }^{[12]}$

On the other hand, conditions of career advancement for nurses could not be provided without nursing managers' support in the working environment. ${ }^{[16,17]}$ Nursing managers confront with two challenges: maintaining experienced nurses and developing healthy working environment. ${ }^{[11]}$ Kramer et al. believe that nursing managers develop indices of nurses' working environment through providing optimal working environment and developing meaningful work with expertise knowledge. ${ }^{[18]}$ Many organisations are providing professional clinical settings that support nurses' career advancement. $^{[6,7]}$ According to Sheikh et al., standards of working environment include communication, collaboration, professional promotion, and empowerment. ${ }^{[19]}$

Understanding contributing factors to nursing career advancement in healthcare organisations could influence on identifying developing working environment for success in career advancement. ${ }^{[20]}$ Although few studies have been conducted on this issue, the role of nurses' working environment in providing the possibility of career advancement is still unknown as it is related to context. ${ }^{[21]}$ Therefore, there is still knowledge gap in the role of working environment in career advancement, and evidence showed that few qualitative studies have been conducted on this topic.

\section{Objective}

This study aimed to explore the role of working environment in nurses' career advancement from nursing mangers' perspectives.

\section{Methods}

\subsection{Research design}

This qualitative study was conducted using interview for data collection and content analysis from nursing managers' perspectives on the role of working environment in nurses' career advancement. Qualitative approach was selected as it is the most appropriate method for describing managers' perspectives on the role of working environment in career advancement. $^{[22]}$

\subsection{Data collection}

All participants took part in the study purposefully and voluntarily. The inclusion criteria include nursing managers with at least 2 years of managerial experience in the levels of head nurse, supervisor, and nurse manager at hospitals. Semistructured interviews were conducted using an interview guide in a private room in participants' working environment. The first interview was begun with a nursing manager with 26 years of working experience who has had rich experience on career advancement. The average time of interviews took between 60 and 90 minutes. This study was conducted from April to September 2014. After 17 interviews, no new theme was found, and data reached to the saturation. Thus, an interview was ended after 18 interviews.

\subsection{Setting and participants}

A purposive sample was selected from participants who were interested in taking part in the study and shares their experi- 
ences on the role of working environment in nurses' career advancement. Eighteen nursing mangers participated in the study with maximum variations in position and managerial history in the levels of head nurse, supervisor, and hospital nurse manager. All participants have been working in teaching hospitals affiliated to Qazvin, Tehran, Shahid Beheshti, and Iran Medical Sciences Universities. Participants' demographic characteristics present in Table 1.

Table 1. The characteristics of participants $(\mathrm{N}=18)$

\begin{tabular}{ll}
\hline Characteristics & N/Mean $\pm S D$ \\
\hline Gender & 5 \\
- Male & 13 \\
- Female & $(42.5 \pm 4.90)$ years \\
Age mean and standard deviation & $(14 \pm 5.00)$ years \\
Mean of work experience and standard deviation & \\
Education & 6 \\
- Bachelor's degree & 12 \\
- Master's degree & \\
Official position & 6 \\
- Hospital nurse manager & 5 \\
- Supervisor & 7 \\
\hline
\end{tabular}

\subsection{Ethical considerations}

This study is a part of PhD study at the University of Rehabilitation and Welfare Sciences, which was approved in the ethics committee of the university. All participants were informed about the purpose of the study, ethical principles of research, and voluntary participation. Written informed consents were obtained from participants for interviewing and recording the interviews. Moreover, permission was obtained from authorities and managers of hospitals before conduction the interviews.

\subsection{Data analysis}

Interviews were transcribed immediately. The primary investigator (the first author) read transcripts several times to reach an overall understanding. Then, transcripts were sent to the members of the research team. Data were analyzed using conventional content analysis. ${ }^{[23]}$ This qualitative method is appropriate for describing phenomena that was selected for this study. Transcription were read line by line and coded by meaningful units. In the first or familiarization stage, we transcribed the data verbatim and read each interview several times to gain a sense of content. Other members of the research team approved codes and meaningful units. Meaningful units formed sub-categories based on similarities and induction method. Finally, sub-categories formed main categories based on similarities and meaningful connections.
Members of the research team participated throughout the process of data analysis.

\subsection{Rigor}

For trustworthiness and rigor in qualitative studies, the following criteria form Guba and Lincoln including credibility, transferability, dependability, and confirm ability of were considered. ${ }^{[24]}$ For credibility, the following criteria were considered: lengthy relationship with participants, memberchecking through sending the transcripts to the interviewees, and debriefing by nursing faculty members experienced in qualitative data analysis. Dependability and confirm ability were carried out through auditing of the interviews. Transferability was provided through rich description of data.

\section{Results}

According to nursing managers' perspectives, working environment had a dual impact on nurses' career advancement. In one hand, working environment had motivating and stimulating role; in the other hand, it had restrictive role in nurses' career advancement. The concept of career advancement has been described from participants' perspectives as: career advancement includes any professional promotion that results in more independency at work, changing of roles, and career promotion with increasing financial benefits. From participants' perspectives, career advancement had a variety dimensions; it is also a unique phenomenon that is different from a person to another one. Development of roles, changing of organizational position, obtaining more desirable position in the organization are considered as an opportunity for self-expression and career capability. For instance, a supervisor with 18 years of experience stated career advancement as: "when you reach a position that feels change in your job, the organization respects you and your opinions. You are important for the organization, and this is career advancement." A head nurse with 14 years of experience said: "career advancement is referred to promotion form an organizational group to a higher group, so that your salary and benefits rose more than the past."

Participants believe that working environment had two distinctive effects: (1) motivating, and (2) restrictive.

\subsection{Motivating and encouraging role}

According to participants, actualizing working environment had motivating and encouraging role for nurses' career advancement. These environments include the following characteristics: the opportunity of career advancement, support, access to education, and desirable organizational atmosphere. The opportunities of career advancement are provided by nurses or healthcare organizations. In such environment, 
nurses are encouraged to create essential opportunities for their promotion. A nurse manager with 22 years of experiences said: "when I saw all personnel are getting master's degree, I told why not me. It seems that there was a competition among nurses to promote their status. I also read and get the Master's degree. Then, this qualification made me to promote".

In addition to nurses' role, organizations can provide the possibility of career advancement through developing regulations and criteria. A nursing manager with 26 years of experience said: “nurses' career advancement made be possible by issuing regulations of nurses' career advancement." Support was another characteristic of working environment that participants considered. Support can be from all sides or from managers and colleagues. In the actualizing working environment, nurses are supported comprehensively. According to our participants, organizational support consists of managers, colleagues, and important others' supportive attitude, behavior, and practice. Such a support facilitates nurses' cooperation and career advancement. A supervisor with 16 years of experience said: “in our ward, I've been supported by both the head nurse and colleagues. They were really kind with me. When I was offered for the supervisory position, all of them supported me. Thus, I accepted the responsibility."

Access to continuing education allows nurses to attend in these courses and facilitates essential conditions for educational evidences in addition to increasing nurses' knowledge and skills. A supervisor with 18 years of experience said: " $a$ lot of educational courses are held at our hospital. Nurses participated in these courses - most of them with credits. So, when taking into account educational credits, most of them have no problem." Another feature of such environment was referred as desirable organizational atmosphere. Participants believed that managers' positive attitude, interpersonal relationship, and management style could affect creating desirable organizational atmosphere. A nursing manager with 20 years of experience said: "the atmosphere is really good in this hospital; nurses feel good, and everyone feels comfort. They come to the office and talk easily. Their relationship is really intimate. As a result, everyone makes attempt to work in the best manner. Most nurses have been able to obtain essential credits for career advancement."

\subsection{Restrictive role}

In the restrictive working environment, nurses confront with barriers for career advancement. Although some nurses promote in such environment, their experiences indicate tolerating tough and up and down trend. According to participants, some features of this environment include high workload, nursing shortage, and limited opportunity for career advancement, lack of support, and lack of access to education. The main challenge that most nursing mangers experienced was increasing workload and nursing shortage, which affect the quality of nursing and decelerate nurses' career advancement. Most of our participants highlighted the adverse impact of nursing staff shortage and heavy workload on career advancement. Nurses who have a heavy workload are not able to enroll in programs that facilitate their career advancement. A head nurse with 16 years of experience said: "I have worked in a hospital in which the number of nursing personnel was very low. So, we had to work in lots of shifts. In addition to charged shifts, we had extra work that made me not to promote easily and promote later than others."

In such environment, opportunities of career advancement are very limited for both nurses and organizations. A nursing manager with 26 years of experience said: "when the rule of career advancement was issued, it was specified for 65\%; thus, all nurses were not taken into account." Nursing managers believed that receiving support from the organization and colleagues is at the least level in restrictive environment, which results in confronting problems in nurses' career advancement. A supervisor with 18 years of experience said: "when I was accepted for Master's degree, I expected matron to support me and decrease my shifts or agree with my educational mission. She not only did not agree with the mission but also did not decrease my shifts. This made me to get Master's degree hard."

In the restrictive working environment, access to continuing education is highly limited. According to the participants, lack of planning and increasing task load and responsibilities are considered as the factors for limited access to continuing education, which lead to delaying in the process of nurses' promotion. A head nurse with 14 years of experience said: "in this hospital, most courses are not based on our educational needs. In addition, we have no opportunity to attend these educational courses due to increasing number of patients and high workload. So, I haven't able to obtain credits of continuing education."

\section{Discussion}

According to nursing managers participating in this study, the role of working environment in nurses' career advancement is emphasized from a variety dimensions. Some perspectives indicate that nurses' working environment with the following characteristics can facilitate nurses' career advancement, which include career advancement opportunities, access to continuing education, desirable organizational atmosphere, and comprehensive support. On the other hand, restrictive working environment creates restrictions for nurses' career 
advancement through limited opportunity of career advancement, lack of support, lack of access to education, high workload, and nursing shortage. These findings are consistent with Adeniran et al. study that identified healthy working environment as the facilitator and unhealthy working environment as the blocker of nurses' career advancement. ${ }^{[7]}$

In this study, managers believe that nursing managers' role influenced on creating working environment providing conditions of nurses' career advancement. Literature review indicates that managers have a major role in creating healthy working environment for nurses' career advancement. ${ }^{[18]}$ McCabe and Neil also founded that managers affect motivation, increasing self-confidence, and professional commitment among nurses. However, these studies did not report that managers affect nurse' career advancement directly. ${ }^{[25,26]}$ Munro indicated that managers influence on increasing nurses' career motivation for career advancement. Kramer et al stated that nursing managers play a role in creating healthy and productive working environment. ${ }^{[18]}$

Nurses' access to continuing education is another important point that participant stated in this study. They believe that continuing education in the working environment results in promoting knowledge and skill that facilitates career advancement. In the actualizing working environment, access to these educations is easy. However, firstly, it is necessary to develop programs that are based on nurses' needs and their efficiency is evaluated. Secondly, nurses' active attending in the education is provided. In the restrictive working environment, such access is not easy as much, or educational programs are not developed and implemented based on nurse's educational needs. Studies showed that healthy working environments make possible nurses to participate in continuing education. ${ }^{[6]}$ Schmalenberg found that continuing education in nurses' working environment results in increasing their clinical competences, so that nurses with Master's degree are effective in creating such environments. ${ }^{[27]}$

Other studies showed that environment with full of career advancement opportunity could provide career advancement for nurses. ${ }^{[4-7]}$ Moran reported that environment without advancement opportunities block nurses' development. ${ }^{[28]}$ Munro reported that participants considered lack of support in the working environment a barrier to nurses' career advancement. Indeed, one of the barriers for nurses' career advancement is lack of support and motivation among nurses. ${ }^{[29]}$ Chong et al. reported that managers have a major role in encouraging nurses for career advancement in the working environment. ${ }^{[11]}$

In this study, participants consider workload and nursing shortage in the working environment as the barriers to career

Published by Sciedu Press advancement. Workload and lack of time decrease essential opportunities for promotion of abilities resulting in increased professional competences. Studies indicate that nurses consider lack of time and high workload in the clinical settings as the barriers of career advancement. Lapeirre found that nurses should have motive, adequate opportunity and time to participate in the programs resulting in career advancement. ${ }^{[30]}$

\section{Limitations}

Like other qualitative studies, the findings of the current study are probably situation-specific and hence of limited transferability.

\section{Conclunsions}

According to the findings of this study, it is essential to explore the role of these concepts in nurses' career advancement. It is recommended to investigate nurses' individual characteristic and competencies for creating motivating working environments.

Working environment could provide appropriate context for nurses' career advancement. Nursing working environment is influenced by organizational policies, nurses' values and attitudes, and nursing managers' roles. When these components are acted accordance to the organizational development and organizational resources development, desirable and motivating environments are provided, which result in personal and organizational development. On the other hand, if these concepts are not integrated and purposeful, organizational conditions and clinical settings fail to facilitate essential context for accelerating nurses' career advancement process, and nurses' working environment will be restrictive for career advancement and organizational development. Healthcare organizations have provided support for the indispensable role of these factors in creating actualizing work environments for nurses.

\section{Authors contribution}

Mohammad Reza Sheikhi, Masoud Fallahi Khoshknab and Farahnaz Mohammadi, Fatemeh Oskouie developed this study concept and design. Mohammad Reza Sheikhi collected the data and Masoud Fallahi Khoshknab and Mohammad Reza Sheikhi analysed the data and Mohammad Reza Sheikhi preparation of manuscript.

\section{Source of funding}

This study was exclusively funded by the University of Social Welfare and Rehabilitation Sciences.

\section{ACKNOWLEDGeMents}

This study was funded by University of Social Welfare and 
Rehabilitation Sciences, Tehran, Iran (Grant No: 732). We would like to gratefully thank the university administrators and staffs as well as the study participants.

\section{CONFLicts OF InTEREST Disclosure}

The authors declare no conflict of interest.

\section{REFERENCES}

[1] Rahimaghaee F, Nayeri ND, Mohammadi E. Managers' roles in the professional growth of Iranian clinical nurses. Nursing \& health sciences. 2010; 12(4): 470-6. PMid: 21210926. http://dx.doi.org /10.1111/j.1442-2018.2010.00561.x

[2] Chen SH, Fu CM, Li RH, et al. Relationships Among Social Support, Professional Empowerment, and Nursing Career Development of Male Nurses A Cross-Sectional Analysis. Western journal of nursing research. 2012; 34(2): 862-82. PMid: 20956582. http://dx.doi.org/10.1177/0193945910384603

[3] Werner JM. Human Resource Development $\neq$ Human Resource Management: So What Is It? Human Resource Development Quarterly. 2014; 25(2): 127-39. http://dx.doi.org/10.1002/hrdq. 2118 8

[4] Adeniran RK, Bhattacharya A, Adeniran AA. Professional excellence and career advancement in nursing: A conceptual framework for clinical leadership development. Nursing administration quarterly. 2012; 36(1): 41-51. http://dx.doi.org/10.1097/naq.0b013e3

[5] Dehghan Nayeri N, Varvani Farahani A, Sharifi N, et al. Effects of a Staff Development Program on Head Nurses' Communication Skills and Job Satisfaction. Nurs Midwifery Stud. 2012; 1(2): 62-6 http://dx.doi.org/10.5812/nms. 8562

[6] Coventry TH, Maslin-Prothero SE, Smith G. Organizational impact of nurse supply and workload on nurses continuing professional development opportunities: an integrative review. Journal of Advanced Nursing. 2015; 2715-2727. http://dx.doi.org/10.1111/jan .12724

[7] Adeniran RK, Smith-Glasgow ME, Bhattacharya A, et al. Career advancement and professional development in nursing. Nursing outlook 2013; 61(1): 437-46.

[8] Allen SR, Fiorini P, Dickey M. A streamlined clinical advancement program improves RN participation and retention. Journal of Nursing Administration. 2010; 40(7/8): 316-22. http://dx.doi.org/10. 1097/NNA . Ob013e3181e93978

[9] Brannick M, Cadle A, Levine EL. 7 Job Analysis for Knowledge, Skills, Abilities, and Other Characteristics, Predictor Measures, and Performance Outcomes. The Oxford Handbook of Personnel Assessment and Selection. 2012: 119.

[10] Cleary M, Horsfall J, Muthulakshmi P, et al. Career development: Graduate nurse views. Journal of clinical nursing. 2013; 22(17-18): 2605-13.

[11] Chong E. Managerial competencies and career advancement: A comparative study of managers in two countries. Journal of Business Research. 2013; 66(3): 345-53.

[12] Drey N, Gould D, Allan T. The relationship between continuing professional education and commitment to nursing. Nurse education today. 2009; 29(7): 740-5. PMid: 19394724. http://dx.doi.org /10.1016/j.nedt.2009.03.008

[13] Sheikhi, Fallahi Khoshknab M, Mohammadi F, et al. Nurse Leaders' Experiences of Implementing Career Advancement Programs for Nurses in Iran. Global Journal of Health Science. 2015; 7(5): 73-79. http://dx.doi.org/10.5539/gjhs.v7n5p73

[14] Ulrich BT, Lavandero R, Hart KA, et al. Critical care nurses' work environments: a baseline status report. Critical Care Nurse. 2006;
[15] Riley JK, Rolband DH, James D, et al. Clinical ladder: Nurses' perceptions and satisfiers. Journal of Nursing Administration. 2009; 39(4): 182-8.

[16] Ezzedeen SR, Ritchey KG. Career advancement and family balance strategies of executive women. Gender in Management: An International Journal. 2009; 24: 388-411.

[17] Kanai-Pak M, Aiken LH, Sloane DM, et al. Poor work environments and nurse inexperience are associated with burnout, job dissatisfaction and quality deficits in Japanese hospitals. Journal of clinical nursing. 2008; 17(24): 3324-9. http://dx.doi.org/10.1111/j $.1365-2702.2008 .02639 . \mathrm{x}$

[18] Kramer M, Halfer D, Maguire P, et al. Impact of healthy work environments and multistage nurse residency programs on retention of newly licensed RNs. Journal of Nursing Administration. 2012; 42(3): 14859. http://dx.doi.org/10.1097/NNA.0b013e31824808e3

[19] Sheikhi, Fallahi Khoshknab M, Mohammadi F, et al. Nures' Experience of Flourishing Work Environment in Career Advancement: A Qualitative Study. JQUMS. 2015; 18(6).[persion]

[20] Ravari A, Bazargan-Hejazi S, Ebadi A, et al. Work values and job satisfaction: A qualitative study of Iranian nurses. Nursing ethics. 2012: 1-11.

[21] Rahimaghaee F, Nayeri D, Mohammadi E. Iranian nurses perceptions of their professional growth and development. OJIN: The Online Journal of Issues in Nursing. 2011; 16(1). http://dx. doi .org/1 $0.1111 / j .1442-2018.2010 .00561 . x$

[22] Graneheim UH, Lundman B. Qualitative content analysis in nursing research: concepts, procedures and measures to achieve trustworthiness. Nurse education today. 2004; 24(2): 105-12. http: //dx.doi.org/10.1016/j.nedt.2003.10.001

[23] Elo S, Kaariainen M, Kanste O, et al. Qualitative Content Analysis. SAGE Open. 2014; 4(1): 1-10. http://dx.doi.org/10.1177/2 158244014522633

[24] Streubert H, Carpenter D. Qualitative Research in Nursing. $4^{\text {th }}$ ed. Philadephia: Lippincott Williams \& Wilkins; 2007.

[25] McCabe TJ, Garavan TN. A study of the drivers of commitment amongst clinical nurses. Training. 2008; 32: 528-68. http://dx.d oi.org/10.1108/03090590810899829

[26] Neill MW, Saunders NS. Servant leadership: enhancing quality of care and staff satisfaction. J Nurs Adm. 2008; 38: 395-400.

[27] Schmalenberg C. Essentials of a productive nurse work environment. Nursing Research. 2008; 27(1): 2-13. http://dx. doi .org/10 . 10 97/01. NNR . 0000280657.04008.2a

[28] Moran P, Duffield CM, Donoghue J, et al. Factors impacting on career progression for nurse executives. Contemporary nurse. $2011 ; 38(1-2)$ : 45-55.

[29] Munro KM. Continuing professional development and the charity paradigm: interrelated individual, collective and organisational issues about continuing professional development. Nurse education today. 2008; 28: 953-61. http://dx.doi.org/10.1016/j.healthpol .2009 .02 .007

[30] LaPierre TA, Zimmerman MK. Career advancement and gender equity in healthcare management. Gender in Management: An International Journal. 2012; 27: 100-18. 